\title{
Domiciliary non-invasive ventilation - is there an optimal interface?
}

\begin{abstract}
Background and aim: The purpose of our study was to ascertain if there were any advantages of the nasal mask (NM) when compared to the full face mask (FFM) interface for subjects requiring non-invasive home mechanical ventilation (NIHMV).

Design and methods: We retrospectively analysed 256 patients who were successfully initiated on domiciliary ventilation between May 2009 and August 2013. The interface initially selected was determined, along with any change in interface after $12 \mathrm{months}$, with gas exchange measurements after 12 and 24months. Hospital admissions, inpatient days, levels of compliance and intolerance to NIHMV were recorded for each 12 month period.
\end{abstract}

Results: Patients opting for the FFM interface used higher NIV pressures, although achieved similar improvements in gas exchange. Levels of compliance, intolerance, and reduction in burden on health care resources was similar at 24 months for each interface, regardless if any change in interface in the intervening period.

Conclusion: There were no differences in overall effectiveness for either NM or FFM interface for people requiring NIHMV.

Keywords: interface, non-invasive ventilation
Volume I Issue 4 - 2014

\section{Comer DM, Mukherjee R}

Directorate of Respiratory Medicine \& Physiology, Heartlands Hospital, UK

Correspondence: Mukherjee R, Directorate of Respiratory Medicine \& Physiology, Birmingham Heartlands Hospital, Birmingham, UK, Tel 0I2I 4243744,

Email rahul.mukherjee@heartofengland.nhs.uk

Received: November 20, 2014 | Published: November 27, 2014
Abbreviations: NIV, non-invasive ventilation; FFM, full face mask; NM, nasal masks; ABG, arterial blood gas

\section{Introduction}

There is no perfect interface for non-invasive ventilation (NIV) The full face mask (FFM) is generally regarded as the most appropriate first-line strategy for the management of acute hypercapnic respiratory failure with NIV. ${ }^{1}$ In this context, the FFM leads to more favourable patient outcomes, such as a lower probability of progression to tracheal intubation, improved tolerance, and more satisfactory gas exchange when compared to the various nasal masks $(\mathrm{NM})^{2,3}$ However, for chronic stable respiratory failure, the most commonly chosen interface used is generally regarded as the NM, followed by nasal pillows, FFM and mouthpieces, primarily on the basis of patient comfort. ${ }^{4,5}$ For both scenarios the ideal interface minimises air leaks, maximises patient comfort, and ensures satisfactory patient-ventilator synchrony. ${ }^{6}$ Considerable technological progress over the last decade has broadened the number and types of interface to achieve these aims. $^{4}$

It is recognised that any dead space rendered by virtue of the internal volume of the interface itself is a considerable problem, ${ }^{7}$ and this varies substantially between the various products available. ${ }^{8}$ Dead space increases with masks which have a larger internal volume, ${ }^{7}$ whereas in contrast, is decreased in masks which have a built-in exhalation port, ideally located over the nasal bridge. ${ }^{5,9}$ These factors have historically rendered NM to be considered the most appropriate option for stable chronic patients undergoing domiciliary NIV. ${ }^{6}$

Despite these findings, in our institution, we have encountered considerable challenges with mouth air leaks with the cephalic NM and nasal pillows in many individuals. Other groups have reported similar findings for subjects on long term nasal bi-level ventilation. ${ }^{10,11}$ We speculate this may be attributed to the higher pressures used for many of our patients that would not have been considered feasible, or indeed necessary, historically. Many of our patients are commenced on domiciliary ventilation after a series of acute admissions with acute hypercapnic respiratory failure, and continue using the same interface which they had been accustomed to while an inpatient. Furthermore, a high proportion of patients who attend our service are elderly, many of whom have neuromuscular disorders, and we have noticed they anecdotally report the modern FFM to be more convenient when tightening the straps to achieve a satisfactory seal. These are relevant observations as evidence which supported the notion that NM should be considered superior were primarily based on studies on relatively young subjects, primarily with chronic obstructive airway disease or chest wall deformities as the aetiology for their respiratory insufficiency. ${ }^{12}$ We therefore question the widely held belief that NM should be considered most appropriate in the first instance when initiating long term NIV. It is also of interest there are more recent reports indicating marginal differences in the clinical effectiveness of the various interfaces. ${ }^{13}$

Evidence which supports the notion that NM is most appropriate for domiciliary NIV is clearly outdated. We hypothesised that, as there is a more diverse population who are now treated for respiratory failure with domiciliary NIV, and with more modern FFM interfaces, the concept that NM are consistently the most appropriate choice of interface should be challenged.

\section{Methods}

\section{Patients and assessments}

Data was collected for 256 patients who were successfully initiated on domiciliary ventilation between May 2009 and August 2013. The underlying cause of respiratory insufficiency, arterial blood gas (ABG) measurements, and overnight oximetry to ascertain if there was evidence of nocturnal hypoventilation, spirometry according 
to the criteria of the European Respiratory Society, and sniff nasal inspiratory pressure for those individuals with neuromuscular disease was all recorded. A prediction of the patient's height was established in those subjects with kyphoscoliosis by substituting height for arm span.

Follow up after 12 months included repeat ABG parameters, repeat spirometry, adverse effects of NIV and repeat sniff nasal aspiratory pressure in neuromuscular patients. Compliance and tolerance to NIV was determined, primarily by "interrogating" of the NIV machine in order to establish the average numbers of hours used per night Ventilator parameters, including inspiratory (IPAP) and expiratory (EPAP) pressures, along with mode of ventilation were recorded. The number of hospital admissions, including the total number of days spent in hospital, in both the year before and in the subsequent year after starting NIV was determined.

The interface chosen deemed most appropriate for each patient was recorded. This was often selected at the discretion of the treating physician, after dialogue with each patient and demonstration of the various options at the outpatient clinic. Requests by the patient at subsequent clinic visits to have their interface changed were recorded. If the patients interface was not changed, and compliance with NIV was adequate (defined as 4 hours NIV use or longer per night according to local practice), it was assumed the interface was satisfactory in terms of patient comfort.

\section{Statistical analysis}

Statistical analysis was performed using SPSS version 17.0 (SPSS inc., Chicago, IL, USA). Data are presented as mean values \pm SD. Comparisons between groups were performed using the unpaired t-test after confirming normality of the data by the D' Agostino-

Table I Patient characteristics and interface selected
Pearson test. A p value of less than 0.05 was considered significant.

\section{Results}

The underlying cause of the respiratory insufficiency is shown in Table 1, along with the interface chosen (NM or FFM). Overall the most popular interfaces when commencing non-invasive ventilation were the Quattro Air and the Quattro FX FFM (ResMed, Oxfordshire, UK). In terms of the NM, the Mirage Soft Gel, followed closely by Swift FX Nano (ResMed, Oxfordshire, UK) were the most popular. In many cases, there were several potential causes of respiratory impairment, and judgement was made on a case by case basis as to the main culprit. In those patients whereby it was impossible to know with sufficient certainty which disease process was most relevant, the aetiology of the respiratory insufficiency was deemed to be multifactorial.

Ventilator settings are shown in Table 2. Pressure support was the most commonly selected mode of ventilation. The improvement in gas exchange and burden of care after 48 months of NIV is shown in Table 3 when those subjects who required a change in interface after 24 months are considered. Corresponding values for those who used the same interface throughout, and so did not have a change in interface after 12 months, is shown in Table 4 . Table 5 shows the findings after 48 months of NIV for all subjects, when comparing the final interface used, regardless if there was a change in interface or not after 12 months from NIV initiation.

The flow chart in Figure 1 indicates the number of patients using either NM or FFM at the initiation of domiciliary NIV, along with numbers who were intolerant and overall level of compliance after 12 months. Corresponding values after the subsequent 12 months, along with any corresponding change in interface, is demonstrated in the third column of the flow chart.

\begin{tabular}{lll} 
& Face mask & Nasal mask \\
\hline Neuromuscular disease & 25 & 32 \\
Obesity-hypoventilation \pm OSA & 28 & 16 \\
Obesity-hypoventilation \pm OSA \& COPD \pm Bronchiectasis & 59 & 42 \\
Chest wall deformity / Previous Polio / Kyphoscoliosis & 26 & 6 \\
Multi-factorial & 19 & 14
\end{tabular}

Table 2 Initial ventilator settings for selected interface

\begin{tabular}{llll}
\hline & IPAP $\left(\mathrm{cmH}_{2} \mathbf{O}\right)$ & EPAP $\left(\mathrm{cmH}_{2} \mathbf{O}\right)$ & Back-up rate range \\
\hline Face mask & $18.4 \pm 1.6 *$ & $6.2 \pm 1.1$ & $12-14$ \\
Nasal mask & $13.9 \pm 2.1$ & $4.9 \pm 1.9$ & $10-14$ \\
\hline
\end{tabular}

Table 3 Gas exchange improvements and burden of care after 24 months of NIV, only considering those subjects who required an interface change at I 2 months follow up

\begin{tabular}{|c|c|c|c|c|c|c|}
\hline & $\begin{array}{l}\text { Rise in } \\
\mathrm{PaO}_{2}(\mathrm{kPa}) \\
\text { from initial } \\
\text { assessment } \\
\text { pre-NIHMV }\end{array}$ & $\begin{array}{l}\text { Reduction in } \\
\mathrm{PaCO}_{2}(\mathrm{kPa}) \\
\text { from initial } \\
\text { assessment } \\
\text { pre-NIHMV }\end{array}$ & $\begin{array}{l}\text { Hospital } \\
\text { Admissions } \\
\text { pre-NIV/year }\end{array}$ & $\begin{array}{l}\text { Hospital } \\
\text { Admissions post- } \\
\text { NIHMV with } \\
\text { second interfacel } \\
\text { year }\end{array}$ & $\begin{array}{l}\text { Hospital I/P } \\
\text { days pre- } \\
\text { NIHMV/year }\end{array}$ & $\begin{array}{l}\text { Hospital I/P days } \\
\text { post-NIHMV with } \\
\text { second interface/ } \\
\text { year }\end{array}$ \\
\hline $\begin{array}{l}\text { Face mask } \\
\text { (from nasal } \\
\text { mask) }\end{array}$ & $1.3 \pm 0.2$ & $2.1 \pm 0.5$ & $4.1 \pm 0.6$ & $2.1 \pm 1.4$ & $32.1 \pm 3.2$ & $15.9 \pm 7.7$ \\
\hline $\begin{array}{l}\text { Nasal Mask } \\
\text { (from face } \\
\text { mask) }\end{array}$ & I. I \pm 0.4 & $1.8 \pm 0.7$ & $4.3 \pm 0.6$ & 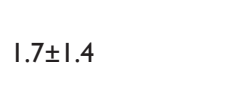 & $34.7 \pm 2.6$ & $14.3 \pm 1.9$ \\
\hline
\end{tabular}


Table 4 Gas exchange improvements and burden of care after 24 months of NIV, only considering those subjects who did not require a change in interface at 12 months follow up

\begin{tabular}{|c|c|c|c|c|c|c|}
\hline & $\begin{array}{l}\text { Rise in } \\
\mathrm{PaO}_{2}(\mathrm{kPa}) \\
\text { from initial } \\
\text { assessment } \\
\text { pre-NIHMV }\end{array}$ & $\begin{array}{l}\text { Reduction in } \\
\mathrm{PaCO}_{2}(\mathrm{kPa}) \\
\text { from initial } \\
\text { assessment pre- } \\
\text { NIHMV }\end{array}$ & $\begin{array}{l}\text { Hospital } \\
\text { Admissions } \\
\text { pre-NIV/year }\end{array}$ & $\begin{array}{l}\text { Hospital } \\
\text { Admissions post- } \\
\text { NIHMV with } \\
\text { second interfacel } \\
\text { year }\end{array}$ & $\begin{array}{l}\text { Hospital I/P days } \\
\text { pre-NIHMV/year }\end{array}$ & $\begin{array}{l}\text { Hospital I/P } \\
\text { days post- } \\
\text { NIHMV } \\
\text { with second } \\
\text { interface / } \\
\text { year }\end{array}$ \\
\hline $\begin{array}{l}\text { Face } \\
\text { Mask }\end{array}$ & I. $7 \pm 0.5$ & $1.7 \pm 0.3$ & $4.7 \pm 1.3$ & $2.7 \pm 1.0$ & $36.1 \pm 4.2$ & $17.9 \pm 6.7$ \\
\hline $\begin{array}{l}\text { Nasal } \\
\text { Mask }\end{array}$ & $1.4 \pm 0.4$ & $1.3 \pm 0.9$ & $4.3 \pm 0.2$ & $2.4 \pm 0.4$ & $31.1 \pm 1.9$ & $|5.7 \pm| .3$ \\
\hline
\end{tabular}

Table 5 Gas exchange improvements and burden of care after 24 months from initial assessment when considering the final interface, regardless if any change in interface required after 12 months. *Statistically different from nasal interface

\begin{tabular}{|c|c|c|c|c|c|c|}
\hline & \multirow{2}{*}{$\begin{array}{l}\text { Rise in } \\
\text { PaO2 }(\mathrm{kPa}) \\
\text { from initial } \\
\text { assessment } \\
\text { pre-NIHMV }\end{array}$} & \multirow{2}{*}{$\begin{array}{l}\text { Reduction in } \\
\text { PaCO2 }(\mathrm{kPa}) \\
\text { from initial } \\
\text { assessment pre- } \\
\text { NIHMV }\end{array}$} & \multicolumn{2}{|c|}{$\begin{array}{l}\text { Hospital Admissions pre- } \\
\text { NIV/year }\end{array}$} & \multicolumn{2}{|c|}{$\begin{array}{l}\text { Hospital I/P days pre-NIHMVI } \\
\text { year }\end{array}$} \\
\hline & & & & \multicolumn{2}{|c|}{$\begin{array}{l}\text { Hospital admissions post- } \\
\text { NIHMV with second } \\
\text { interface/year }\end{array}$} & $\begin{array}{l}\text { Hospital I/P days } \\
\text { post-NIHMV } \\
\text { with second } \\
\text { interface/year }\end{array}$ \\
\hline Face Mask & $1.4 \pm 0.4$ & $2.3 \pm 0.5$ & $4.5 \pm 0.9$ & $2.7 \pm 1.4$ & $32.1 \pm 3.2$ & $18.9 \pm 7.7$ \\
\hline Nasal Mask & $I . I \pm 0.2$ & $2.1 \pm 0.6$ & $3.9 \pm 0.7$ & $2.3 \pm 0.8$ & $25.7 \pm 2.6$ & $22.7 \pm 1.9$ \\
\hline
\end{tabular}

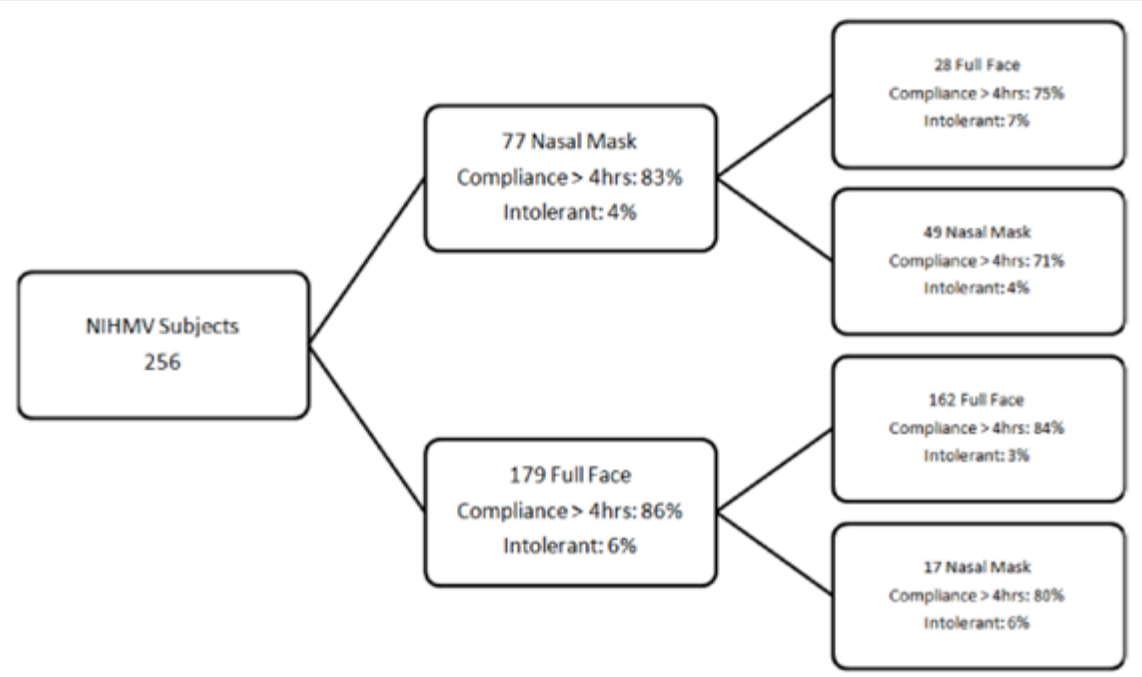

Figure I Number of subjects using nasal or face masks initially, the interface used after I2months, along with compliance and number intolerant of NIV after 24 months of NIV.

\section{Discussion}

Data which support the notion that the NM should be the initial interface of choice for domiciliary NIV has not been re-assessed in the context of technological progress in interface design and a patient population with more profound respiratory insufficiency who are now supported with long term NIV. It seems reasonable to assume that acceptance of any given interface is likely enhance compliance of NIV. ${ }^{16,14}$ Our study has demonstrated the effectiveness of the FFM for individuals requiring NIHMV, and when compared to the NM, there were no differences in terms of improvements in gas exchange, degree of compliance, numbers intolerant, and mitigation of health care utilisation. Although NM interfaces clearly have a role, our data indicates that the FFM, despite having a greater dead space, is well tolerated, and appears to be equally effective by people requiring NIHMV.

Over the last decade, a variety of interfaces have been developed in an effort to optimise patient comfort. Evidence supporting the notion that NM interfaces are consistently more appropriate for long term NIV is limited..$^{15}$ In fact, at least in the context of obstructive 
sleep apnoea, two studies demonstrated the face mask to be equally effective compared to the nasal mask, with no differences in compliance and overall side-effect profile. ${ }^{16,17}$ For NIHMV, we are only aware of two studies which evaluated the attributes of the various interfaces for individuals with chronic hypercapnic stable respiratory failure, one of which was published 14years ago. In terms of comfort and tolerance, the earlier of these studies indicated that the nasal masks were the most favourable, although the FFMs achieved more impressive improvements in gas exchange. Nasal pillows were shown to be more comfortable than the FFM, but the observed differences were not significant. ${ }^{12}$ The latter of these studies reported higher levels of comfort with the nasal interface in people with chronic respiratory insufficiency, although there were no differences in terms of maintenance of gas exchange or preventing sleep disordered breathing, the latter determined by full polysomnography. ${ }^{18}$ Therefore, considering the evidence overall, neither interface consistently emerges as a more appropriate modality for the delivery of NIHMV.

We report no significant differences in gas exchange for the NM when compared to the FFM. However, it is pertinent to be cognisant of the fact that higher pressures were used for those subjects opting for the FFM, which itself was statistically significant. With this in mind, it could feasibly be argued that perhaps the absence of an improvement in gas exchange in the FFM over the NM could be interpreted as the FFM as being inferior, at least for this particular endpoint. The only way to truly assess this would be to compare the FFM with the NM using exactly the same pressures. However, as there were no differences in improvements in gas exchange, whether there was a change in interface or not, and considering every permutation of interface over a 48 months period, this observation substantiates the notion that the NM and FFM are equally effective in the delivery of NIHMV for individuals with respiratory insufficiency.

For the purpose of our study, we have made the assumption that satisfactory compliance with NIHMV for any given individual subject, or alternatively improved or at least stabilised gas exchange, is a reflection of a more satisfactory comfort of the selected interface. The most striking limitation of our study is the fact we have not used validated questionnaire, specifically addressing the challenges with each NIV interface. Despite this shortcoming, however, we feel the endpoints are valid, important, and of relevance to this patient group. Furthermore, although strictly speaking we cannot categorically state individuals could have been established on a comfortable and satisfactory interface, and yet had minimal improvements in gas exchange purely as a consequence of progression of their underlying disease, we feel this to be a more unlikely explanation, or at least these individuals represents a minority of the study population, particularly considering the time period of our study.

Our work has other important limitations, most strikingly the different patient populations in each group which almost certainly has an impact on the findings. For example, there were more patients who were obese using the FFM than the NM. Different pressures were used for the FFM and the NM subjects, and due to its retrospective nature, we cannot determine accurately the reasons for the change in interface. However, in the absence of demonstrating very striking differences in relevant patient centred outcomes, the NM did not emerge as an overall superior interface for people requiring long term home ventilation.

In conclusion, although the general consensus is for the NM to be considered the interface of choice for NIHMV, with recent progress in interface design, along with a different patient population now supported with NIHMV, the FFM should be considered equal in terms of interface choice. We propose that, on the basis of our data, the NM should no longer dominate this arena.

\section{Acknowledgements}

None.

\section{Conflict of interest}

The author declares no conflict of interest.

\section{References}

1. Meduri GU, Cook TR, Turner RE, et al. Non-invasive positive pressure ventilation in status asthmaticus. Chest. 1996;110(3):767-774.

2. Kwok H, McCormack J, Cece R, et al. Controlled trial of oronasal versus nasal mask ventilation in the treatment of acute respiratory failure. Crit Care Med. 2003;31(2):468-473.

3. Girault C, Briel A, Benichou J, et al. Interface strategy during non-invasive positive pressure ventilation for hypercapnic acute respiratory failure. Crit Care Med. 2009;37(1):124-131.

4. Nava S, Navalesi P, Gregoretti C. Interfaces and humidification for noninvasive mechanical ventilation. Respir Care. 2009;54(1):71-84.

5. Elliott MW. The interface: crucial for successful non-invasive ventilation. Eur Respir J. 2004;23(1):7-8.

6. Schonhofer B, Sortor-Leger S. Equipment needs for non-invasive mechanical ventilation. Eur Respir J. 2002;20(4):1029-1036.

7. Saatci E, Miller DM, Stell IM, Lee KC, et al. Dynamic dead space in face masks used with noninvasive ventilators:a lung model study. Eur Respir J. 2004;23(1):129-135.

8. Fraticelli AT, Lellouche F, L'Her E, et al. Physiological effects of different interfaces during noninvasive ventilation for acute respiratory failure. Crit Care Med. 2009;37(3):939-945.

9. Schettino GP, Chatmongkolchart S, Hess DR, et al. Position of exhalation port and mask design affect $\mathrm{CO}_{2}$ rebreathing during noninvasive positive pressure ventilation. Crit Care Med. 2003;31(8):2178-2182.

10. Richards GN, Cistulli PA, Ungar RG, et al. Mouth leak with nasal continuous positive airway pressure increases nasal airway resistance. $\mathrm{Am} \mathrm{J}$ Respir Crit Care Med. 1996;154(1):182-186.

11. Teschler H, Stampa J, Ragette R, et al. Effect of mouth leak on effectiveness of nasal bilevel ventilatory assistance and sleep architecture. Eur Respir J. 1999;14(6):1251-1257.

12. Navalesi P, Fanfulla F, Frigerio P, et al. Physiologic evaluation of noninvasive mechanical ventilation delivered with three types of masks in patients with chronic hypercapnic respiratory failure. Crit Care Med. 2000;28(6):1785-1790.

13. Sferrazza Papa GF, Di Marco F, Akoumianaki E, et al. Recent advances in interfaces for non-invasive ventilation: from bench studies to practical issues. Minerva Anestesiol. 2012;78(10):1146-1153.

14. Pravinkumar SE. A face that matters in distress: interface selection for acute non-invasive ventilation. Crit Care Med. 2009;37(1):344-346.

15. Chai CL, Pathinathan A, Smith B. Continuous positive airway pressure delivery interfaces for obstructive sleep apnoea. Cochrane Database Syst Rev. 2006;18(14):CD005308.

16. Anderson FE, Kingshott RN, Taylor DR, et al. A randomized crossover efficacy trial of oral CPAP (Oracle) compared with nasal CPAP in the management of obstructive sleep apnea. Sleep. 2006;26(6):721-726. 
17. Khanna R, Kline LR. A prospective 8 week trial of nasal interfaces vs a novel oral interface (Oracle) for treatment of obstructive sleep apnea hypopnea syndrome. Sleep Med. 2003;4(4):333-338.
18. Willson GN, Piper AJ, Norman M, et al. Nasal versus full face mask for non-invasive ventilation in chronic respiratory failure. Eur Respir $J$. 2004;23(4):605-609. 